\title{
Proposals for special issues welcomed
}

\author{
Jan Olhager $\cdot$ Scott Shafer
}

Published online: 23 May 2014

(C) Springer Science+Business Media New York 2014

Keywords Operations management $\cdot$ Practice $\cdot$ Research . Theory

Operations Management Research is now accepting proposals for special issues. A key aspect of a special issue is that it is aligned with the purpose of OMR, i.e., a special issue topic must reflect the need for contributions to theory and practice as well as address a contemporary topic.

The journal takes a broad view of operations including manufacturing operations, service operations, supply chain operations, retail operations, as well as health care operations, humanitarian logistics, and other types of organizations including not-for-profit, government, and public organizations.

The journal also welcomes perspectives such as global operations, right-sourcing and right-shoring, sustainability, behavioral OM, risk, big data and analytics, innovation, and emerging economies, as well as interfaces with other areas such as business or corporate strategy, marketing, finance, product development, R\&D, finance, and accounting.

Furthermore, OMR has no preferred research methodology. Instead, OMR welcomes research that utilizes a variety of methodologies including case, action, survey, mathematical modeling, simulation, etc. However a special issue could focus on the application of a particular methodology to operations management (e.g., simulation studies in operations management) or depending on the topic encourage the use of multiple research methodologies.

The editorial team for a special issue should consist of two or more individuals that (together) are very familiar with the topic, e.g. by combining areas of specialization if the special issue is concerned with the intersection of two topical areas.

A proposal for a special issue should contain the following information:

- Proposed title

- Proposed guest editor team

- Background and motivation (200-400 words)

- Proposed reviewers (minimum 5 qualified reviewers)

- Proposed milestones and time plan

We will review incoming proposals on an on-going basis and hope to publish one or two special issues each year.
J. Olhager $(\bowtie)$

Department of Industrial Management and Logistics,

Lund University, Box 118, 22100 Lund, Sweden

e-mail: Jan.Olhager@tlog.tth.se

S. Shafer

School of Business, Worrell Professional Center, Wake Forest

University, P.O. Box 7659, Winston-Salem, NC 27109, USA

e-mail: shafersm@wfu.edu 